\title{
A review on quality by design
}

\author{
Sachin L. Darkunde \\ M-Pharm, Department of Quality Assuranc, Dr. D. Y. Patil Institute of Pharmaceutical Sciences and Research, Pimpri, Pune, \\ Maharashtra, India
}

Corresponding Author:

Email: sachindarkunde05@gmail.com

\begin{abstract}
Quality by design (QbD) is an essential part of the modern advance to pharmaceutical quality. Quality has been given an importance by all regulatory body for pharmaceutical products. Quality means customer satisfaction in terms of service, products, and process. QbD is best key to build a quality in all pharmaceutical products. This paper gives idea about the Pharmaceutical Quality by Design (QbD) and describes use of Quality by Design to ensure quality of Pharmaceutical Analysis. Under this concepts of be throughout design and growth of product, it is important to identify desire product performance report Target product profile (TPP), Quality Target product profile (QTPP) and identify critical quality attributes (CQA). To recognize the impact of raw material critical material attributes (CAM), critical process parameters (CPP) on the CQAs and identification and control sources of changeability. USFDA launched a pilot programme in 2005 to permit participating firms a prospect to submit chemistry, manufacturing, and controls (CMC) of NDA information representing application of QbD. QbD has its perspectives to contribute the drug design, development, and manufacture of high-quality drug products. In the present review basic consideration of the QbD approach, its historical background, and regulatory needs are discussed. In detail explanation of elements of QbD i.e. method intent, design of experiment, and risk assessment is given. The foundation of Quality by Design is ICH Guidelines. It is based on the ICH Guidelines Q8 for pharmaceutical development, Q9 for quality risk management, Q10 for pharmaceutical quality systems. It also gives application of Quality by Design in pharmaceutical development and manufacturing of pharmaceuticals.
\end{abstract}

Keywords: Quality by design, Critical Quality Attributes, Pharmaceutical Analysis, Design Of Experiment, Risk Assessment, Regulatory.

\section{Introduction $^{1-6}$}

Quality: In Quality by Design, Quality is important word. So Quality is "standard or suitability for intended use." This term includes such attribute of the identity, potency, and purity.

Quality by Design: A lot of approaches to the development of pharmaceutical products and their subsequent manufacture has been advocated by the US FDA and the International Council Harmonization (ICH). This approach has been mounted 'Quality by Design' (QbD) and it defined as-

"A systematic approach to development that begins with predefined objective and emphasizes product and process understanding and process control, based sound science and quality risk management"
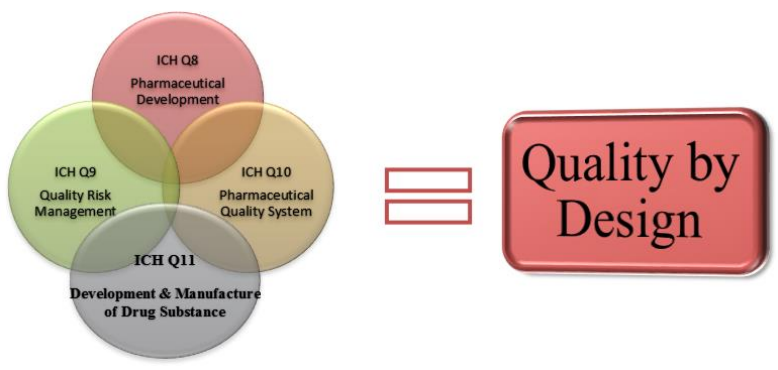

\section{Fig.1: Content of Quality by Design}

The conception of "Quality by Design" (QbD) was outlined as an approach which covers a better scientific
Pharmaceutical industries aware of product Quality, Safety, and Efficacy. Product quality has been increasing by implement scientific tools known as QbD (Quality by Design). Scientific approaches can offer the clear and sufficient knowledge from product development to manufacturing. These $\mathrm{QbD}$ tools will minimize the hazard by increasing the output and quality. Nowadays $\mathrm{QbD}$ approach has been successfully enforced in common formulation development. USFDA has released specific $\mathrm{QbD}$ guidance for immediate and extended release drug products as well as biotechnological products. Regulatory authorities are always proposing the implementation of ICH quality guidelines such as Q8, Q9, Q10 \& Q11. 
limits of understanding during the development phase and using the knowledge obtained during the life-cycle of the product to work on a constant improvement environment. QbD describes a pharmaceutical development approach pertaining to formulation design and development and manufacturing processes to care of the prescribed product quality. Guidelines associated with mathematical models are used to ensure the establishment and use of the knowledge on the subject in an independent and integrated way.

QbD doesn't essentially mean less analytical testing, rather it means that proper analysis at the right time, and is based on science and risk assessment. Implementation of QbD helps to develop rugged and robust (strong) method that helps to go with $\mathrm{ICH}$ therefore for that reason pharmaceutical industries are adopting the conception of QbD. Factors that have an effect on the robustness are considered for development of analytical method in QbD environment. This approach facilitates continuous improvement in method. Parallel opportunities of the applying of QbD to analytical technique as that of manufacturing process are available in literature. It put forth approach like target profile, Critical quality attributes (CQA), design space, risk assessment are applicable to analytical method also. Through its not adopted by all pharmaceutical industries it's future perspective as a result of it's become necessary by regulatory bodies. Voluntary adoption of this concept by industries is feasible attributable to its varied advantages and easy compliance regulatory authority. Pharmaceutical research and manufactures of America (PhRMA), Analytical Technical group (ATG) and European Federation of Pharmaceutical Industries and Association (EFPIA) provide clear ideas regarding parallel implementation of QbD to analytical method.

Applications of QbD in analytical method
development

Implementation of $\mathrm{QbD}$ helps to develop rugged and robust/strong method that helps to go with $\mathrm{ICH}$ guidelines hence for that reason pharmaceutical industries are adopting this concept of QbD. This approach facilitates continuous improvement in method.

1. Chromatographic techniques like HPLC ( For stability studies, method development, and determination of impurities in pharmaceutical)

2. Karl Fisher titration for determination of moisture content

3. To Biopharmaceutical processes

4. Dissolution studies

5. Hyphenated technique like LC-MS

6. Advanced techniques like mass spectroscopy, UHPLC, capillary electrophoresis

7. Analysis of genotoxic impurity

\section{Advantages of QbD}

\section{For industry}

1. In case of variation in conditions the developed method will be more robust which gives greater level of confidence.

2. It helps to increased understanding of the method.

3. This approach offer bigger transfer success when method is transferred from research level to quality control department.

4. Design space concept avoids the post-approval modification which may cause to pay a high price for any of the firm.

5. It provides a space an area for invention of latest techniques by continuous improvement throughout life cycle.

For Food and Drug Administration

1. Provide for more flexibility in decision making

2. Enhance scientific base for analysis

3. Ensures decisions made on science \& not on observed information

4. Offer higher consistency

\section{Pharmaceutical aspects: Traditional vs. QbD Approach ${ }^{3,8}$}

Table 1: Difference Between Traditional vs. QbD Approach

\begin{tabular}{|l|l|}
\hline \multicolumn{1}{|c|}{$\begin{array}{c}\text { Traditional Analytical Method } \\
\text { Development }\end{array}$} & \multicolumn{1}{|c|}{$\begin{array}{c}\text { QbD (Lifecycle) Analytical Method } \\
\text { Development }\end{array}$} \\
\hline $\begin{array}{l}\text { Methods validated as a check-box tool as } \\
\text { defined in International Conference on } \\
\text { Harmonization (ICH) Q2 guidance, } \\
\text { Validation of Analytical Procedure: Text and } \\
\text { Methodology }\end{array}$ & $\begin{array}{l}\text { Suitability of a method demonstrated } \\
\text { against an analytical target profile, which } \\
\text { defines the specific characteristics and } \\
\text { criteria required by the process control } \\
\text { strategy }\end{array}$ \\
\hline $\begin{array}{l}\text { Effect of variation in method parameters on } \\
\text { performance of method is less understood }\end{array}$ & $\begin{array}{l}\text { A science based structured approach for } \\
\text { identifying and exploring method variables } \\
\text { and their effect (method design and } \\
\text { qualification stages) }\end{array}$ \\
\hline $\begin{array}{l}\text { Method transfer seen as separate exercise } \\
\text { from validation }\end{array}$ & $\begin{array}{l}\text { Method-transfer activities seen as } \\
\text { components of the life cycle approach and } \\
\text { considered change control exercises; }\end{array}$ \\
\hline
\end{tabular}




\begin{tabular}{|l|l|}
\hline & $\begin{array}{l}\text { appropriate method installation and } \\
\text { verification actions determined by } \\
\text { assessment (method performance } \\
\text { verification stage) }\end{array}$ \\
\hline $\begin{array}{l}\text { The terms e.g; method verification, method, } \\
\text { method validation and revalidation are } \\
\text { confusing in traditional approach }\end{array}$ & $\begin{array}{l}\text { In lifecycle-approach more clear terms } \\
\text { aligned with process validation and } \\
\text { equipment qualification terminology are } \\
\text { used. }\end{array}$ \\
\hline $\begin{array}{l}\text { Method validation used to performed one- } \\
\text { time event performed on completion of } \\
\text { method development. }\end{array}$ & $\begin{array}{l}\text { Method lifecycle validation used to } \\
\text { performed all activities that ensure a } \\
\text { method produces fit-for-purpose data during } \\
\text { the whole lifecycle (i.e; from development } \\
\text { through to on-going routine operating } \\
\text { environment and includes knowledge } \\
\text { transfer from a sending unit) }\end{array}$ \\
\hline $\begin{array}{l}\text { Method transfer includes activities performed } \\
\text { to transfer a method from sending unit to a } \\
\text { receiving unit and do demonstrate } \\
\text { equivalence between the two units }\end{array}$ & $\begin{array}{l}\text { Method installation includes activities } \\
\text { performed to ensure effective method set up } \\
\text { in the routine operating environment and } \\
\text { includes knowledge transfer from sending } \\
\text { unit }\end{array}$ \\
\hline $\begin{array}{l}\text { Method verification involves ensuring } \\
\text { pharmacopeial methods operate under actual } \\
\text { condition of use; revalidation is performed } \\
\text { after changes for validation characteristics } \\
\text { likely to be affected }\end{array}$ & $\begin{array}{l}\text { Method performance verification involves } \\
\text { demonstrating that a method performs as } \\
\text { intended following a change in the methods } \\
\text { operating conditions or operating } \\
\text { environment }\end{array}$ \\
\hline
\end{tabular}

Flow Of Quality By Design ${ }^{2,9,7}$

Define Target product profile and quality target profile

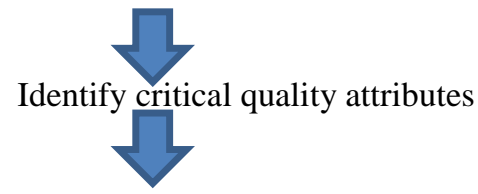

Carry out risk assessment linking material attributes and process parameter to CQAs

Fig. 2: QbD Flow chart

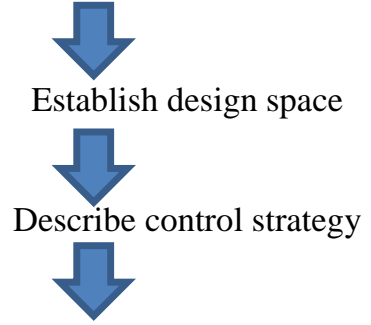

Life cycle management and continuous improvement

Key Aspects of QBD ${ }^{6,7,8}$

\section{Analytical target profile (ATP)}

$\mathrm{QbD}$ is a systematic approach to product, process design and development; therefore it begins with determination of method goal or method intent. During this stress is given on the products and process understanding, ATP is way for new method development. It describes the strategy needs for method requirements which are expected to be measured. In normally the goal of the chromatographic method is separation, quantification and identification of drug substance, impurity or degradent. Impurity is taken into account to be the critical quality attributes (CQA). While dealing with traces of impurities it will be helpful to have knowledge of previous synthetic and manufacturing processes and all alternative possible pathways which lead to the encounter of impurities. The method demand are will be accuracy, precision, robustness and so on as delineated in ICH guideline. As like conventional method, QbD method additionally want detail data information of analyte like its solubility, Pka, $\mathrm{P}^{\mathrm{H}}$, UV chromophore, stability. Supported these data rigorous method goals as ATP can be set to obtain a best method. This provides frame 
work to method development that helps for further planning. ATP is in complete accordance with $\mathrm{ICH}$ guideline. Therefore Analytical Target Profile is the combination of all performance criteria required for the intended analytical application that direct the method development process. An ATP associate degree ATP would develop for every of the attributes outlined with in the management strategy. The Analytical Target Profile defines what the method has to measure and to what level the measurement is required (i.e. performance level characteristics, such as precision, accuracy, working range, sensitivity, and the associated performance criterion). Any method conforming to the ATP is considered suitable. The ATP will be regarded as the focal point in all stages of the analytical life cycle.

\section{Critical Quality Attributes (CQA) ${ }^{6}$}

Factors that directly have an effect on the quality and safety of the products are first sorted out, and its potential impact on method development is studied. CQA will be understood analysed by Understanding of the products and method. If drug product contains the impurity which may have direct impact on quality and safety of drug product it is being considered the critical quality attribute for the HPLC method development of that particular drug compound. According to Schweitzer et al safety and efficacy can be achieved by demonstration measurable control of quality attributes i.e. products specification, intermediate specification, process control.

\section{Quality Risk Assessment ${ }^{2,4,9}$}

1. The analysis of the risk to quality should be based on scientific knowledge \& it provides safety to the patient.

2. Describes systematic processes for the assessment, control, communication $\&$ review of quality risks.

3. Applies over the products lifecycle, development, manufacturing \& distribution.

4. Method mentioned in ICH Q9 guideline are as follows-

5. Failure Mode Effects Analysis (FMEA);

6. Failure Mode, Effects and Criticality Analysis (FMECA);

7. Fault Tree Analysis (FTA);

8. Hazard Analysis and Critical Control Points (HACCP);

9. Hazard Operability Analysis (HAZOP);

10. Preliminary Hazard Analysis (PHA);

11. Risk ranking and filtering;

12. Supporting statistical tools.

\section{Critical Material Attributes (CMA) And Critical Process Parameters (CPP) $)^{4,8,13}$}

1. A material attributes is critical when a practical change in that attribute can significantly impact the quality of the output material.
2. CPPs are responsible for ensuring the CQAs \& it is identified from a list of potential CPPs using risk assessment.

3. A process parameters is critical when it has a high impact on a critical quality attributes.

Three categories for parameters or attributes:

a. Critical parameters:- A realistic change in parameter can cause the product to fail to get QTPP is critical parameter.

b. Non-critical parameter:- No failure in QTPP determined the within the potential operating space \& no interactions with other parameters in the established suitable range.

c. Unclassified parameters:- The criticality of unclassified parameters is undetermined or unknown. The additional data are needed to classify an unclassified parameter as critical or non-critical.

Risk assessment is link between input process variable and CQA. Following tools are come under risk assessment they are as follows:

1. Failure mode effect analysis (FMEA)

2. Ishikawa or fishbone diagram,

3. Pareto analysis.

A FMEA can then be implemented to rank the variables based on risk and to select the process parameters with higher risks for further studies to gain greater understanding of their effects on Critical Quality Attributes. An Ishikawa or fishbone diagram is employed to spot all potential variables; they are as follows raw materials, instrumental factors, and environmental factors, which can have an impact on a particular CQA. Pareto charts were utilized for quantitatively distinguish the impact of every issue on the chosen CAAs. Main goal of chromatographic method development is identification and separation of compound. In QbD approach the emphasis is given on rugged and robust method through risk assessment.

Design Space: ${ }^{6}$ A Design space is defined as, "Multidimensional combination and interaction of input variables (e.g. material attributes and process parameters) that have been demonstrated to provide assurance of quality". A design space may build for a single unit operation, multiple unit operations, or for the entire process. According to FDA guideline, defining design space is optional since the product and process understanding can be established without a formal design space, nevertheless, above approach can assist to better understanding and attain overall control of a system.

\section{Used of Design Space}

1. Linkage between process inputs (inputs variables and process parameters) and critical quality attributes. 
2. Used for one or more unit operation(s) or up to complete process.

3. Can be implemented before or after MA.

4. Proposed by Applicant.

5. Working between the design space: not considered as a change.

6. Subject to regulatory approval and assessment.

\section{Analytical QbD Method Validation:,}

$\mathrm{AQbD}$ method validation approach is that the validation of analytical method over a range of different API batches. It uses both DoE and MODR knowledge for designing method validation for all kind of API manufacturing changes without revalidation. The approach provides the required ICH validation elements as well as information on interactions, measurement uncertainty, control strategy, and continuous improvement. This approach requires fewer resources than the traditional validation approach without compromising quality.

Advantages of adopting QbD method:

1. This approach provides greater transfer success when method is transferred from research level to quality control department.

2. The developed method will be more robust which provide higher level of confidence in case of variations in conditions.

3. It helps for increased understanding of the method.
4. Design space concept eliminates the post-approval changes which may cause to pay a high cost for any of the firm.

5. It provides a space for invention of new techniques by continuous improvement in whole life cycle.

6. It provides higher compliance with regulatory authorities.

Application of QbD of in Analytical Method Development is suggested by Reid et al (Phizer USA) known as AQbD (Analytical Quality by Design) Workflow. According to Reid et al there are multiple approaches and options to method development like utilization of the different use of software, stationary, phase, columns etc. according to them no single approach can be considered as "correct" approach, however, more systematic approach will give a better understanding of the separation space and robustness of the method faster than less systematic approaches. The most important factor is the development method must be suitable for its intended purpose is shown from the method development and must ensure the method performance as required. The method need (e.g. purpose, specificity, sensitivity, cycle time, accuracy, and precision) must be well established, and these requirements are used to build a method that meets the need of the program.

They suggested AQbD work flow as shown in the following fig.

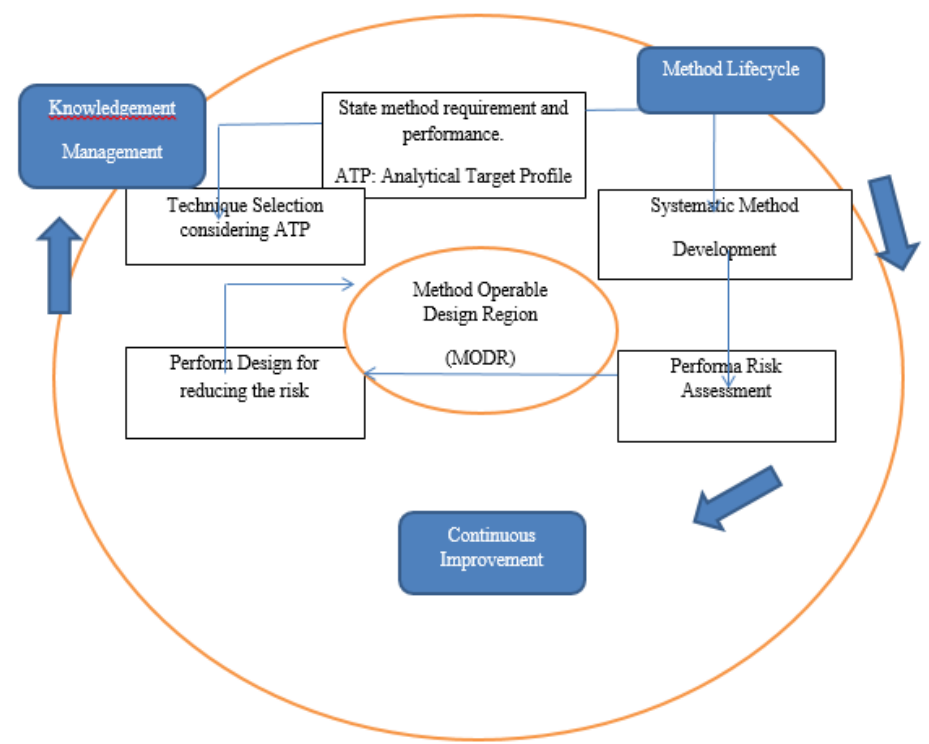

Fig. 3: AQbD workflow by George L. Reid (Pfizer USP)

An analytical method development in an AQbD framework implement following five steps:

a. The $1^{\text {st }}$ step- Defines analytical target profile where the method requirement and performance criteria are shown. Based upon the required of the method, a suitable instrument technique can be chosen which will allow the method to provide the ment performance.

b. The $2^{\text {nd }}$ step- After selecting a acceptable analytical technique, systematic method will be developed for the sample preparation and for analysis through variety of experiments. The objectives of activity experiment are to roughly gain knowledge of robustness and set the method condition. 
c. The $3^{\mathrm{r}}$ step- The knowledge gained in method development will then be implemented in risk assessment. The objective of risk assessment is to spot risk factors that should be experimentally evaluated in a design of experiment (DOE).

d. The $4^{\text {th }}$ step- The DOEs help to establish Method operable design region (MODR) and a control strategy. The concept MODR suggested by Reid et al is synonymous to Design Space. Any place in the MODR will be consider as the Normal Operating Condition (NOC) for the method, and the MODR \& NOC will be verified and Validated.

e. The $5^{\text {th }}$ but continuous step in AQbD involves knowledge management i.e. knowledge acquired from method optimization, development, verification, and use should be collected utilized and transferred thorough the life cycle of the method.

\section{Applications of Quality by Design ${ }^{15}$}

1. For Chromatographic technique

a) In determination of impurity

b) In screening of column used for chromatography

c) In development of HPLC method for drug products substance

d) In capillary electrophoresis

e) In stability studies

f) In UHPLC

2. For hyphenated technique

a) In LC-MS method development

3. In bioanalytical method development

4. In dissolution studies

5. For spectroscopic measurement

a) In mass spectroscopy

b) In IR spectroscopy

c) In handling complex spectroscopic data

6. In modified release products

7. In tableting process

8. Nanosuspension preparation

9. In analysis of API and Excipients

10. In Biopharmaceuticals

\section{Conclusion}

The goal of a well-characterized method development effort is to develop a reliable method that can be implemented with a high degree of assurance to consistently produce data meeting predefined criteria when operated within defined boundaries. QbD can be applied to the development and evaluation of analytical methods. AQbD tools are as follows ATP, CQA, Method Optimization and Development with DoE, MODR, and Control Strategy with Risk assessment, Method validation and Continuous Method Monitoring (CMM) and continuous improvement. QbD requires not only the right ATP but also risk assessment and usage of right tools and performing the appropriate quantity of work within proper time lines. Analytical method development and validation by QbD plays an important role in the pharmaceutical industry for ensuring the product quality. The result of $A Q b D$ is the understanding from product development to commercial production. Scientist can effectively identify the risk initially so that quality can be increased. This new QbD process provides the opportunity for much greater regulatory flexibility in the future. The method performance criteria could potentially be registered instead of the method itself. The method used could be referred to as an example of how to attain the desired method performance criteria. Any modification to this method would be covered by internal change control procedures.

\section{References}

1. Nadpara NP, Thumar R V, Kalola VN, Patel PB. Review Article Quality By Design (Qbd): A Complete Review. 2012;17(2):20-8.

2. Woodcock J, The concept of pharmaceutical quality American Pharmaceutical Review, 7(6), 2004,10-5.

3. Chavan SD, Pimpodkar N V, Kadam AS, Gaikwad PS, Pharm PD. Research and Reviews : Journal of Pharmaceutical Quality Assurance Quality by Design. 2015;1(2):18-24.

4. Roy S (2012) "Quality by Design-Holistic concept of concept of building quality in pharmaceuticals". Int. J Pham Biomed Res 3:100-108.

5. Woodcock J. The concept of pharmaceutical quality. American Pharmaceutical Review,7(6), 2004,10-5.

6. Q9: Quality Risk Management. ICH Harmonized Tripartite Guidelines. International Conference on Harmonization of Technical Requirements for Registration of Pharmaceuticals for Human Use, 2006.

7. Q10: Pharmaceutical Quality System, ICH Tripartite Guidelines. International Conference on Harmonization of Technical Requirements for Registration of Pharmaceuticals for Human Use, 2007.

8. Sangshetti J N, Chitlange S S, Zaheer Z, Quality by Design in Pharmaceuticals, $1^{\text {st }}$ edition, August 2015.

9. Nishendu P et al. (2012) "A complete review of Quality by Design”. Int J Pharm Sci Rev Res 17:20-28.

10. Huang J, Kaul G, Cai C, Chatlapalli R, Hernandez-abad $\mathrm{P}$, Ghosh K, et al. Quality by design case study : An integrated multivariate approach to drug product and process development. 2009;382:23-32.

11. Nishendu P. Nadpara, Rakshit V. Thumar, Vidhi N. Kalola, Parula B. Patel. International Journal of Pharmaceutical Sciences Review and Research,Rev. Res., 2012;17(2);20-8.

12. Lawrence X. Yu. Pharmaceutical Research, 2008;25(4):781-91.

13. Sangshetti JN, Deshpande M, Arote R, Zaheer Z, Shinde DB. Quality by design approach : Regulatory need. Arab J Chem, 2014.

14. Munson J, Gujral B, Stanfield CF, A review of process analytical technology (PAT) in the U.S. pharmaceutical industry. Current Pharmaceutical Analysis, 2, 2006,40514.

15. Sinica DP, Gholve SB, Ajgunde RR, Bhusnure OG, Thonte SS. Pelagia Research Library Analytical method development and validation by $\mathrm{QbD}$ approach $-\mathrm{A}$ review. 2015;6(8):18-24. 